\title{
The Role of Transabdominal Sonography in the Diagnostics of Choledocholithiasis: Compared to Endoscopic Retrograde Cholangiopancreatography
}

\author{
Gafarov RI ${ }^{1}$ and Kanan Yusif-zada $\mathrm{KR}^{2 *}$ \\ ${ }^{1}$ Department of Radiology, Military Hospital of the State Border Service, Azerbaijan \\ ${ }^{2}$ Department of General Surgery, Military Hospital of the State Border Service, Azerbaijan
}

*Corresponding author: Prof Dr Kanan Yusif Zada, MD, PhD, MBA, FACS, Head of Military Hospital State Border Service, Baku, Azerbaijan

\begin{abstract}
Common bile duct stone (CBDS) or choledocholithiasis ( $\mathrm{ChL}$ ) is one of the major pathologies that lead to serious complications, and accurate and early diagnosis is very important. ChL diagnostics is based on clinical, laboratory and instrumental examinations. We used transabdominal songraphy (TAUS) for detecting CBDS and comparing it with endoscopic retrograde cholangiopancretography (ERCP).
\end{abstract}

Keywords: Choledocolithiasis; TAUS; ERCP

\section{Introduction}

Common bile duct stone (CBDS) or choledocholithiasis (ChL) is one of the major pathologies that lead serious complications and accurate, early detection is very important. According to ethiology, there are primary or secondary ChL. $10 \%$ of the ChL cases mentioned in literature are the primary and $90 \%$ of them are secondary ChL. The primary CBDS is associated with biliary stasis (bile duct stricture, papillary stenosis) and infection in bile duct, whereas secondary CBDS appear due to the migration of a stone from the gallbladder. With higher prevalence among women at the ratio of $2: 1$, the prevalence rate of gallstone disease is $5-25 \%$ and in $20 \%$ of the gallstone cases in choledocholithiasis appear simultaneously [1-5]. Clinical manifestation of ChL is similar to acute and chronic cholelithiasis exacerbated with mechanical jaundice [4,5]. Early diagnosis of the disease helps preventing such lethal complication as cholangitis, liver abscess, pancreatitis, as well as reducing the volume of surgical intervention. ChL diagnostics is based on clinical, laboratory and instrumental examinations.
Instrumental examinations differ from the others because of complexity and invasion. Non-invasive methods of CBDS detection include intravenous cholangiography, scintigraphy, transabdominal sonography (TAUS), computer tomography (CT) and magneticresonance cholangiopancreatography (MRCP), while invasive methods include endoscopic retrograde cholangiopancreatography (ERCP), endoscopic ultrasonography (EUS), intraoperative cholangiography (IOC). Nonof this method solitarily provides for comprehensive detection of ChL [6-8]. ERCP, being both diagnostic and curative intervention, is currently accepted as a "gold standard" in many medical facilities. However due to being invasive, it potentially leads to complications like pancreatitis, bleeding, perforation, cholangitis in $16 \%$ of cases [9-11]. In order to reduce the number of unnecessary ERCP procedures the American Society for Gastrointestinal Endoscopy recommends referring patients in three risk groups based on outcomes of clinical, laboratory and radiologic examinations: 
a) High risk ( $>50 \%)$ - apparent jaundice, cholangitis, CBDS or dilated common bile duct on TAUS

b) Mid-level risk (10\%-50\%) - elevated liver function tests values, patients age above 55 years and signs of biliary pancreatitis

c) Low risk group $(<5 \%)$ - big stone in gallbladder, pancreatitis, no signs of jaundice and normal liver function tests value in biochemical analysis of blood.

It is shown that one sign from high risk group or at least two signs from the mid-level risk group is an indication for ERCP and signs in low risk group are the proper indication for cholecystectomy [4,5,12-14]. TAUS in detection of ChL, although used for many years as a "from easy to complicate" as a non-invasive, radiation free, "easy" accessible and relatively cheap screening method, is still well used method $[4,6,15,16]$. Although TUAS is compared with other non-invasive methods of ChL diagnostics, there are not many articles on comparing it with ERCP taken as a "gold standard".

\section{Objective of the Study}

Determination of diagnostic potential of trans-abdominal ultrasonography in detection of choledocholithiasis through verification in comprassion with ERCP.

\section{Materials and Methods}

We performed a retrospective analysis of 97 patients that have passed examination and treatment in our clinic over the period of 2016-2018 years with 43 of them have been excluded as they passed TAUS and MRCP in other clinic; out of remaining 54 patients were women of 25-86 years of age and men of 34-86 years of age.

Ultrasound was performed by $3.5-5.5 \mathrm{MHz}$ frequency, convex transducer with B-mode with tissue harmonics optimization. In emergency cases, the examination was performed immediately, whereas planned examinations were performed 6-8 hours after last meal. Examinations were performed in multiple positions with patient laying on the back, on the right and left side, deep breath and distended abdomen (subcostal, intercostal). Besides intra and extra-hepatic bile ducts, gallbladder, liver and pancreas are also evaluated during examination. The diameters of common bile ducts have been measured visualizing in longitudinal projection at the wider portion, the normal diameter of the duct has been taken as $\leq$ $6 \mathrm{~mm}$. ERCP was performed under general anesthesia, X-ray images were evaluated together with radiologist.

\section{Results of the Research}

All patients complained on jaundice, pain in upper right quadrant (URQ) and dyspepsia. Biochemical analysis of the blood showed elevation of bilirubin and liver function tests value. Sonography showed choledochus dilatation in 48 patients, 46 of them were confirmed by ERCP. There was no choledochus dilatation in 6 patients on TAUS, confirmed by ERCP in 4 of them with other two having minimal choledochus dilation (Figure 1). Thus, according to our studies, the TAUS sensitivity of choledochus dilation was 95,83\%; specificity 66,67\%; positive predictive values (PPV) 95,83\%; negative predictive values (NPV) 66,67\%. Choledocholithiasis was found in 48 out of 54 patients by TAUS, 42 out of them were confirmed by ERCP with no choledocholithiasis in 6 patients. TAUS denied choledocholithiasis in 6 patients, while ERCP confirmed it only in 1 out of them (Figure 2). In 6 TAUS positive and 5 TAUS negative patients with no stone observed on ERCP, a tumor and spasm of Vatter, tumor of the head of pancreas and papillitis were observed. So according to our studies TAUS sensitivity was 97,67\%; specificity 45,45\%; PPV 87,5\% and NPV $83,33 \%$. In 30 patients TAUS showed one stone in CBD and in 18 patients - two or more stones. ERCP detected one stone in 28 patients, in 14- several stones located one after the other (Figure 3).

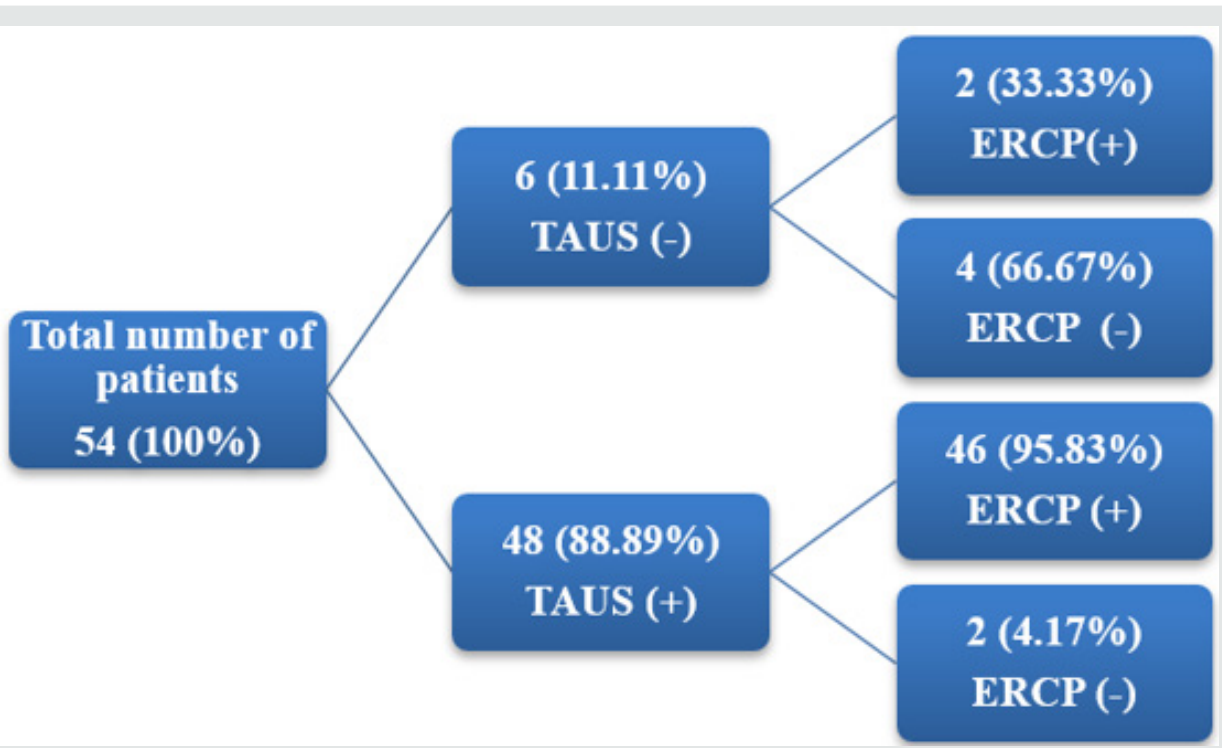

Figure 1: Choledochus dilation (TAUS vs ERCP). 


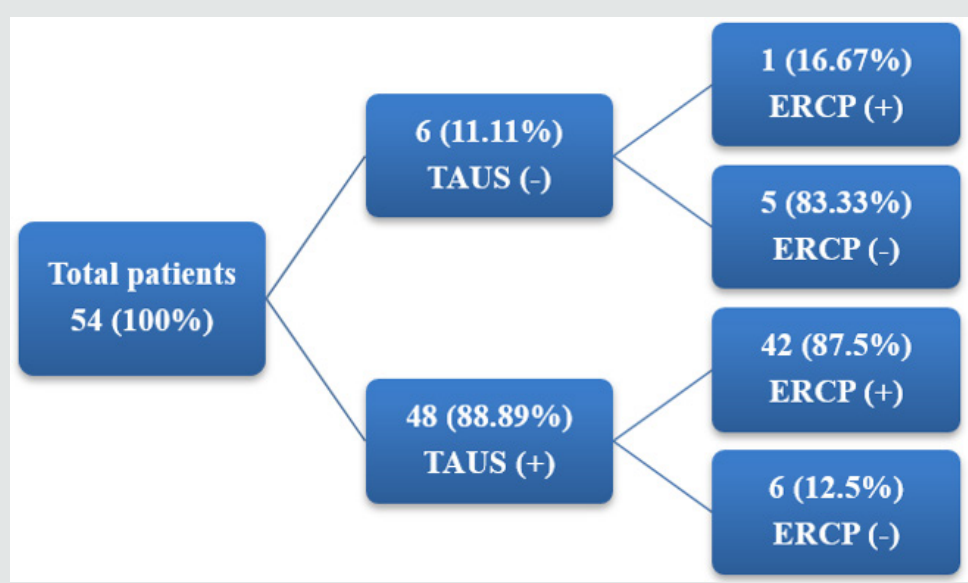

Figure 2: Choledocholithiasis (TAUS vs ERCP).

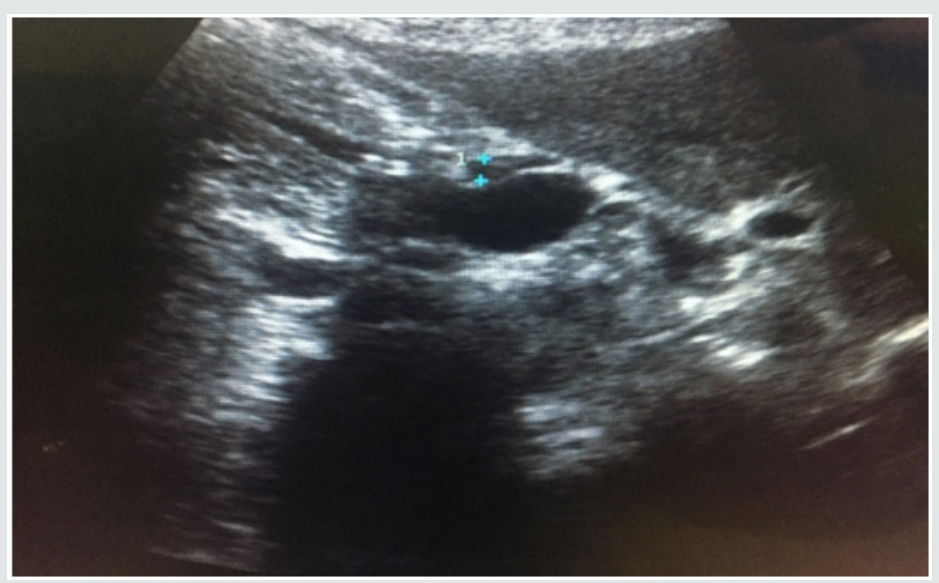

Figure 3: Choledochus diameter $5.2 \mathrm{~mm}$ and 2-3 microlit within according to TAUS.

\section{Discussion}

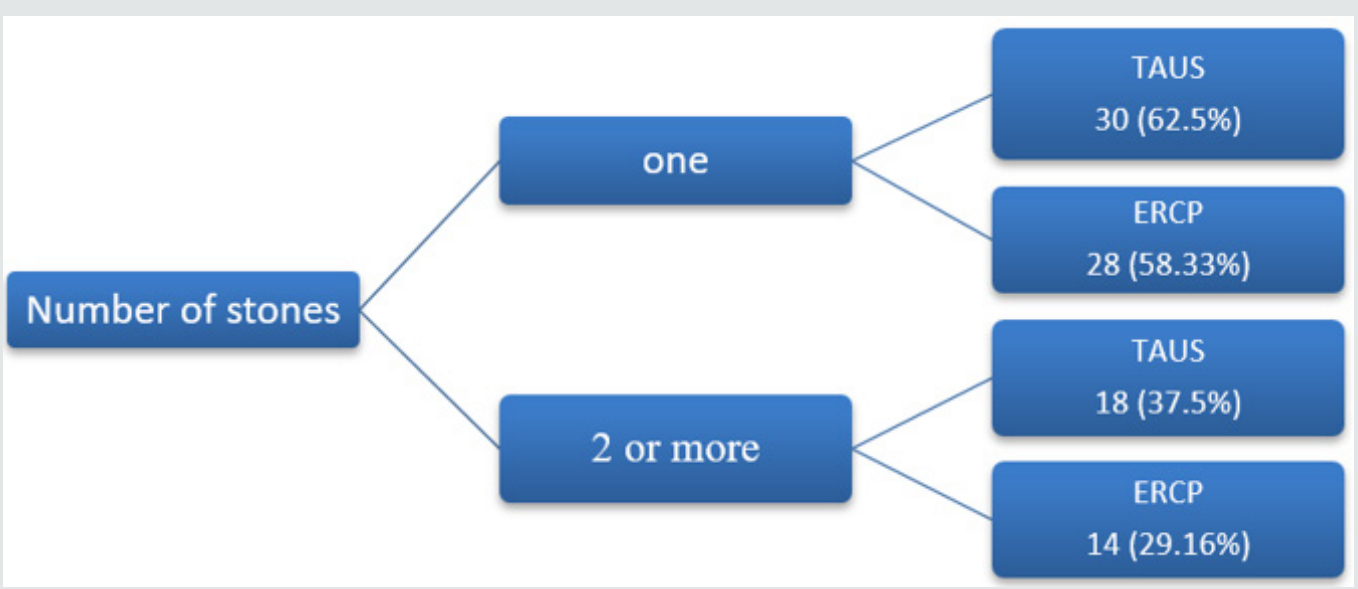

Figure 4: The number of stones during choledocholithiasis (TAUS vs ERCP).

TAUS plays an important role as a screening method for CBDS detection because of no ionizing radiation and no requirement of contrast injection. In our study choledocholithiasis in 42 patients detected by TAUS were confirmed by ERCP. PPV (87.75\%) in ChL detection was close to that of O Conor et al. (93\%) [17], Tandon et al. (90\%) [18]. Sensitivity of TAUS in our study was $97.67 \%$, which is slightly higher than that of Lindsellet al. (84\%) [19], Koenigsberg et al. (82\%) [20]. In 6 false positive cases, not confirmed by ERCP, 4 out of them had limitations associated with detecting stones on cholangiograms during dilated choledochus (Figures 4 \& 5), while 2 had artefacts on TAUS, presumably related to gas at distal choledochus and acoustic shadows of stones in the gallbladder, falling on to the choledochus. Using TAUS as a method of primary examination for the evaluation of gallbladder, liver and pancreas 
during obstructive jaundice, detection of metastasis (MTS) and limphadenopathies, identification of causes for dilation of intraand extrahepatic bile ducts is very urgent. Mani S et al. [21] note the informative value of TAUS as $59 \%$ as result of study with 37 patients, whereas Pickuth et al. [22] speak about 82\%. Kisli E et al. [23] during with study with 58 patients had published with informative value of TAUS as $83 \%$. In this article represents about more informative value of TAUS with big size of bile stone and choledochus diameter. Most of authors also mention less informative value of TAUS in case of non-concremental obstruction of distal part of choledochus (major papilla). The main reason of this considered to the gases in the ampule of the duodenum. The difference in the number of concrements are assumed to happen due to a number of concrements being located one next to each other leading to a single acoustic echo, while size of stone differ due to irregular shape of stones.
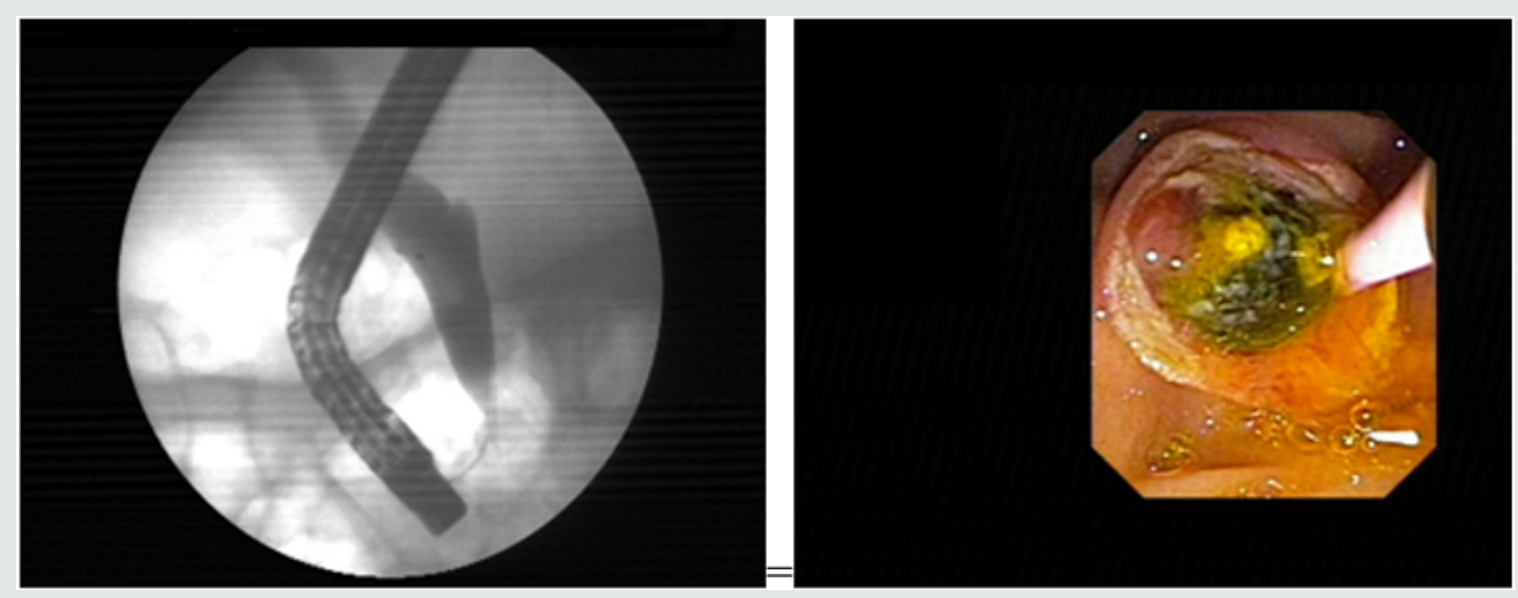

Figure 5: Endoscopic retrograde cholangiogram and endoscopic stone extraction.

\section{Conclusion}

We think that during ChL, TAUS, along with being a primary screening method, while is detected sonographically, substitutes "from simple to complicated" principle-based screening with "simple and complicated" and prevents referring patients to ERCP without using other non-invasive examination methods.

\section{References}

1. Ko CW, Lee SP (2002) Epidemiology and natural history of common bile duct stone and prediction of disease. Gastrointest Endosc 56: 165-169.

2. Shaffer EA (2005) Epidemiology and risk factors for gallstone disease: has the paradigm changed in the 21st century? Curr Gastroenterol Rep 7: $132-140$

3. Gurusamy K, Sahay SJ, Burroughs AK, Davidson BR (2011) Systematic review and meta-analysis of intraoperative versus preoperative endoscopicsphincterotomy in patients with gallbladder and suspectedcommon bile duct stones. Br J Surg 98: 908-916.

4. Taha AM, Salah MF, Hiwa AH (2016) The accuracy of transabdominal ultrasound in detection of the common bile duct stone as compared to endoscopic retrograde cholangiopancretography. The Journal of Gastroenterology 6: 275-299.

5. UfukB Kuzu, BülentÖdemiş, SelçukDişibeyaz (2017) Management of suspected common bile duct stone: diagnostic yield of current guidelines. HPB 19: 126-132.

6. Rumack CM, Wilson SR, Charboneau JW, Levine D (2011) Diagnostic Ultrasound ( $4^{\text {th }}$ edn), Mosby, Maryland Heights, Azerbaijan.

7. Peng WK, Sheikh Z, Paterson Brown S, Nixo SJ (2005) Role of Liver FunctionTests in Predicting Common Bile Duct Stones in Acute Calculous Cholecystitis. British Journal of Surgery 92: 1241-1247.

8. Sgourakis G, Dedemadi G, Stamatelopoulos A, Leandros E, Voros D (2005) Predictors of Common Bile Duct Lithiasis in Laparoscopic Era. World Journal of Gastroenterology 11: 3267-3272.
9. Christensen M, Matzen P, Schulze S, Rosenberg J (2004) Complications of ERCP: a prospective study. Gastrointest Endosc 60: 721-731.

10. Vandervoort J, Soetikno RM, Tham TC, Wong RC, Ferrari AP (2002) Risk factors for complications after performance of ERCP. Gastrointest Endosc 56: 652-656.

11. Cohen S, Bacon BR, Berlin JA, Fleischer D, Hecht GA (2002) ERCP for diagnosis and therapy. Gastrointest Endosc 56: 803-809.

12. Maple JT, Ben Menachem T, Anderson MA, Appalaneni V, Banerjee S (2010) The role of endoscopy in the evaluation of suspected choledocholithiasis. Gastrointest Endosc 71: 1-9.

13. Abboud PA, Malet PF, Berlin JA, Staroscik R (1996) Predictors of Common Bile Duct Stones Prior to Cholecystectomy: A Meta-Analysis. Gastrointestinal Endoscopy 44: 450-457.

14. Cohen ME, Slezak L, Wells CK, Andersen DK, Topazian M (2001) Prediction of Bile Duct Stones and Complications in Gallstone Pancreatitis Using Early Laboratory Trends. The American Journal of Gastroenterology 96: 3305-3311.

15. Maple JT, Ben Menachem T, Anderson MA, Appalaneni V, Banerjee S (2010) The Role of Endoscopy in the Evaluation of Suspected Choledocholithiasis. Gastrointestinal Endoscopy 71: 1-9.

16. Costi R, Sarli L, Caruso G, Iusco D, Gobbi S (2002) Preoperative Ultrasonographic Assessment of the Number and Size of Gallbladder Stones: Is It a Useful Predictor of Asymptomatic Choledochallithiasis? Journal of Ultrasound in Medicine 21: 971-976.

17. O Connor HJ, Hamilton I, Ellis WR, Watters J (1986) Ultrasound Detection of Choledocholithiasis: Prospective Comparison with ERCP in the Postcholecystectomy Patient. Gastrointestinal Radiology 11: 161-164.

18. Tandon BN, Rana S, Acharya SK (1987) Bedside Ultrasonography: A LowCost Definitive Diagnostic Procedure in Obstructive Jaundice. Journal of Clinical Gastroenterology 9: 353-356.

19. Lindsell DRM (1990) Ultrasound Imaging of Pancreas and Biliary Tract. The Lancet 335: 390-393. 
20. Koenigsberg M, Wiener SN, Waizer A (1979) The Accuracy of Sonography in the Differential Diagnosis of Obstructive Jaundice: A Comparison with Cholangiography. Radiology 133: 157-165.

21. Mani S, Rananavare R, Parikh S (1996) Sonographic evaluation of common bile duct stones: prospective comparison with endoscopic retrograde cholangiopancreatography. Bombay Hospital Journal 38: 2-5.
22. Pickuth D, Spielmann RP (2000) Detection of choledocholitiasis: comparison of unenhanced spiral CT, US, and ERCP. Hepato gastroenterology 47: 1514-1517.

23. Kisli E, Söylemez Ö, Aydın M (2002) Koledoktaşlarınıntanısında ERCP vesonografininyeri. The Medical Journal of Kocatepe 2: 151-154.

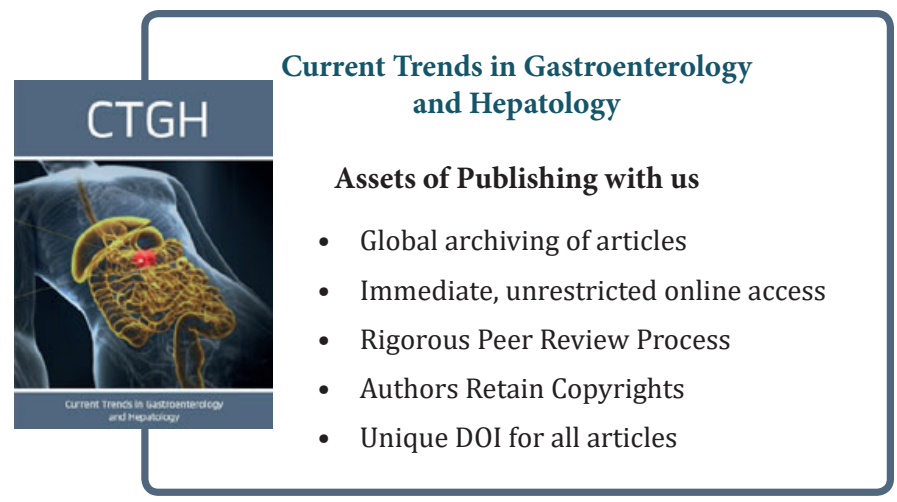

